\title{
O GOVERNO LULA E A INDICAÇÃO DE MINISTROS PARA O SUPREMO TRIBUNAL FEDERAL
}

Álvaro Filipe Oxley da Rocha

\begin{abstract}
Resumo
O presente artigo objetiva realizar algumas observações a respeito das indicações do Governo Lula às vagas de Ministro do Supremo Tribunal Federal brasileiro, a partir da abordagem preliminar dos conceitos de campo jurídico e político, acrescentando considerações sobre o atual mecanismo legal de indicação dos agentes que integram esse órgão de Estado, além discutir algumas das motivações e estratégias utilizadas.
\end{abstract}

Palavras-chave: Governo Lula; Ministros; Supremo Tribunal Federal; Política.

\begin{abstract}
This article aims to make some observations about the indications of President Lula's government for the posts of Minister of the brazilian Federal Suprem Court. The analysis begins with the definition of political and legal fields. Therefore, it will be developed some considerations on the current legal mechanism for appointing the individuals that will belonging to that Court. Furthermore, we discuss some of the motivations and decision strategies used to this purpose.
\end{abstract}

Keywords: Lula Government; Ministers; Brazilian Suprem Court; Politics.

\section{Introdução}

Como destaca Taylor (2007), no Brasil não existe, entre intelectuais e analistas políticos, o persistente desprezo pelos Tribunais, observado em muitos países centrais, e que causou um atraso significativo no desenvolvimento de estudos das relações políticas dos Tribunais com os agentes e organismos das demais instâncias do poder político. Essa atitude, entretanto, de algum modo, se reflete entre nós, na constatação de que ainda poucos pesquisadores das Ciências Sociais, e ainda menos da Ciência Política, se apercebam da relevância desse ator político, deixando assim, de incluí-lo em suas referências de trabalho, ou mesmo como objeto central de suas pesquisas. Entretanto, a maioria concordará com o fato de que o governo Lula realizou importantes intervenções na dinâmica social brasileira, durante a sua trajetória, nos últimos oito anos; nesse período, pelo menos aparentemente, se tornaram mais sólidos os alicerces de uma prática legislativa mais democrática, mantiveram-se os padrões estáveis de 
economia instituídos durante o governo de Fernando Henrique Cardoso, e desenvolveram-se muitos estudos em Ciência Política, enfocando as relações do Executivo nacional com o Legislativo, ou o Congresso, a dinâmica partidária interna do mesmo, as interações mais ou menos estáveis desses agentes com o Executivo federal brasileiro.

Embora durante todo esse período, paralelamente, se tenha evidenciado cada vez mais claramente a influência objetiva do Judiciário, e em especial do Supremo Tribunal Federal (STF), no nível mais alto do jogo político nacional, as interações entre Legislativo e Executivo, com o Judiciário, continuam pouco estudadas, embora já existam avanços (VIANNA, BURGOS e SALLES, 2007; SADEK, 2006, e RIBEIRO e ARGUELHES, 2009), nesse sentido. Destacamos, nessa dinâmica, as relações entre o governo Lula e o Supremo Tribunal Federal, em razão da existência do mecanismo constitucional de indicação dos Ministros que integrarão o referido Tribunal. Nesse sentido, e sem pretender esgotar o tema ${ }^{1}$, o propósito do presente artigo é fazer um rápido levantamento dessa dinâmica, e tecer algumas considerações acerca do propósito, e das interpretações possíveis das nomeações ocorridas durante o governo Lula, de modo a contribuir para o aprofundamento da compreensão desse tema, hoje extremamente relevante. Preliminarmente, apresentamos uma definição ampla do conceito de campo social, e a seguir, mas especificamente, de campo jurídico e político, com o fim de embasar algumas das análises apresentadas. Desse modo, o presente trabalho, não deve ser visto como uma análise definitiva do objeto, mas, antes, como um incentivo ao desenvolvimento do tema, em trabalhos posteriores, por este ou por outros pesquisadores.

\footnotetext{
1 Nesse sentido, é obrigatório referir-se, no Brasil, ao recente trabalho de diversos autores, como Maria da Gloria Bonnelli (2005), Andrei Koerner (1998), Marenco e Dal Ros (2008), Fabiano Engelmann (2010) e Frederico Almeida (2005); no plano internacional, Yves Dezalay e Bryant Garth (1997), Jacques Commaille (1994), David Trubek et. al. (1994), Vauchez e Willemez (2007), e os inclusos na revista Droit et Scoieté, intitulada Bourdieu e o Direito; todos autores e trabalhos de alta qualidade, mas que, infelizmente, não é possível incluir devidamente, no reduzido espaço de um único artigo.
} 


\section{Campo sociais em luta}

Uma noção prévia de campo social é de muita utilidade, na análise das interações em foco. Preliminarmente, deve-se esclarecer que, ao se tratar dessa noção, é necessário separá-la de acepções tradicionais, como as da física, segundo a qual campo é uma região do espaço onde se exerce um força determinada, ou da psicologia social, onde campo é um conjunto de processos psíquicos que constituem um sistema dinâmico, para chegar à noção de campo em sociologia. Para esta última ciência, entretanto, deve-se ter presente que esse termo adquire um significado muito extenso e deixa, assim, de ser preciso; costuma ser associado aos sentidos de domínio e de sistema ${ }^{2}$. Para a maioria dos sociólogos, mantém-se uma idéia básica de dinâmica das forças sociais, relacionadas com um aspecto de disputa entre os agentes. A estrutura interna de cada campo social estabelece os valores e metas a serem considerados como objeto de disputa entre os agentes, pelos padrões de pensamento e formação desses agentes, e não há como reduzir os valores de um campo aos valores de outro campo, em função do treinamento recebido pelos agentes para que possam encontrar orientação dentro do campo, conhecer e reconhecer os agentes acima e abaixo de si na hierarquia e dominar os mecanismos de mobilidade internos ao campo. Bourdieu (1989) esclarece que os investimentos para a inserção no campo com freqüência independem do agente, sendo definidos muitas vezes desde a origem, pela família. Entretanto, não se trata apenas de investimentos do ponto de vista do capital econômico, mas também do ponto de vista de outros capitais, como o capital cultural (PINTO, 2000), que depende muito mais de investimentos em tempo de dedicação à sua aquisição, e de um capital social, que pressupõe os anteriores e permitirá, muitas vezes por cuidadosas manobras, estabelecer naturalmente contatos, ter acesso a pessoas, oportunidades, eventos, etc. nas quais o agente será percebido como um igual, se for aprovado nas verificações muitas vezes informais dos outros agentes, igualmente interessados em possíveis contatos e

2 Destacamos que a noção de campo aqui utilizada é a desenvolvida por Pierre Bourdieu (1989), a qual em nada se assemelha à de Niklas Luhman, em sua Teoria dos Sistemas. 
oportunidades trazidos em potencial pelo novo integrante do campo. Desse somatório resultará a formação de um habitus, ou um sistema interno de referências que permitirá ao agente inserir-se nas disputas do campo com razoável probabilidade de sucesso. Dentro dessa noção deve constar a possibilidade de avaliar a correlação de forças estabelecida no campo, definindo os procedimentos a adotar, avaliando o retorno de investimentos nas diversas formas de capital e projetando desse modo os lucros a auferir. O autor aponta a situação específica de cada campo abordado, identificando-a com a orientação dos agentes que ocupam as posições mais altas na hierarquia do campo, e que surge claramente ao se indicar as instituições envolvidas. Mas há que se destacar também as estratégias adotadas por esses agentes para a realização de seus objetivos, ligados aos objetivos oficiais do campo. A adoção de estratégias mais ou menos rígidas, mais ou menos flexíveis em relação às demais instituições e seus agentes, relacionada à identidade entre os mesmos, em geral forjada em lutas anteriores, possibilita o estabelecimento ou não de novas estratégias, visando a manutenção do campo com o equilíbrio dos interesses dos agentes, o que pode determinar ações e lutas abertas ou silenciosas entre os grupos de agentes. Desse modo é que a estrutura do campo está sempre em disputa, pois o êxito das ações empreendidas determina a nova distribuição do capital específico associado ao campo, e assim estabelece as possibilidades de ascensão ou decadência de carreiras, projetos, pretensões, etc., sustentados por agentes ou grupos específicos. O monopólio da violência legítima associada a cada campo, e em especial ao campo jurídico dentro do campo estatal, não é questionado pelos agentes, pois é tido como definitivo. Obter e utilizar externamente instrumentos de pressão ou mesmo de abalo das hierarquias internas ao campo, significa ser o agente excluído pelos demais, interessados em conservar os mecanismos conhecidos e para eles acessíveis, de distribuição do capital do campo. No caso do campo jurídico, a intromissão de pressões externas do campo político, freqüentemente veiculadas via mídia, por exemplo, tende a ser ignorada pelos agentes, pois o acesso ao campo não está disponível aos agentes 
que não apresentem as condições exigidas pela lógica interna, para fins de produzir o efeito de reconhecimento e conseqüente interação, o que significa que deve o candidato a integrante do campo submeter-se aos interesses e à avaliação dos agente que já o integram. Entretanto, essa indiferença à ação da mídia não pode ocorrer, no campo político. Essas ações do campo jornalístico são consideradas legítimas pelos agentes do campo político, pois representaria esta uma opinião pública, cuja existência não questionam, avaliando seus resultados pela lógica eleitoral, pois a manutenção desses agentes em suas posições depende da legitimação externa, submetida periodicamente a processos eleitorais, fortemente influenciados pela mídia (BOURDIEU, 1997).

A posição dos agentes dominantes dentro do campo, entretanto, é apenas relativamente tranqüila, pois a luta constante por espaço e pelos lucros advindos da distribuição do capital específico do campo procura desestabilizar os elementos de sua conservação, levando-os a reafirmar suas posições pelo discurso associado à posição específica e abrindo espaço à crítica, que se constitui em poderoso instrumento de transformação, que, entretanto, como descreve o autor, não chega (e não poderia chegar) a comprometer a existência do campo. O senso comum observa a atitude normalmente conservadora dos agentes que ocupam os postos mais altos das hierarquias, sem explicar, entretanto, o que justifica essa tendência. A ocupação desses postos significa o engajamento na tarefa de manter e valorizar a força do campo específico. Desse modo, esses agentes não podem ser pessoalmente acessíveis, e suas manifestações serão raras, ambíguas e lacunosas. A defesa do capital cultural específico, decorrente da produção de um bem cultural determinado, enseja, assim, um discurso fortemente ortodoxo, capaz de atingir o objetivo tanto quanto à conservação dessa forma de capital como quanto à manutenção das posições de seus agentes emissores no campo. As lutas em torno desse capital e os procedimentos utilizados em sua distribuição, porém, fazem surgir a necessidade de abrir algum espaço para o discurso de legitimação de novos agentes. Para aumentar suas chances de consagração junto aos futuros pares, esses agentes deverão mostrar ser dignos de confiança, 
mas também, e principalmente, ser capazes de apresentar propostas novas, reformadoras, originais, que atestem domínio da linguagem específica e capacidade de superação dos limites culturais relativos à forma específica de capital em disputa; mas, ainda assim, o novo agente deve continuar mostrando-se previsível e submisso ao controle desses pares. É preciso destacar que essa mecânica estabelece condições para a ascensão de novos agentes, mas o aspecto que mais nos interessa é o de que ela estabelece também as condições para a transformação do próprio campo. Nesse sentido, as estratégias de desenvolvimento pessoal se mostram profundamente ligadas às estratégias de transformação do campo, em razão de não estarem os novos agentes ainda diretamente comprometidos com a estabilização institucional e, pois, com o discurso da ortodoxia conservadora. Produzem-se, desse modo, as condições para o que o autor chama de ruptura crítica.

Pelo discurso crítico, podem surgir elementos inquietantes e mesmo capazes de subverter a ordem de manutenção sustentada pelos agentes já estabelecidos no campo, mas também surgem elementos úteis às modificações consideradas pelos mesmos agentes como oportunas e até mesmo necessárias. É nesse sentido que as manifestações dos agentes da ortodoxia produzem, diante do discurso crítico, um discurso de defesa interessado, visto em especial no campo político como discurso de direita ou do direito, na acepção jurídica do correto, ou do mais adequado. E não poderia ser diferente, dado que da posição do agente no campo, em contraposição às soluções sugeridas por seu habitus, ou treinamento específico, só é possível emitir esse discurso.

O jogo dentro do campo inclui o risco de sua subversão, mas se mantém sob controle, pois a manutenção do jogo representa o interesse de todos os agentes envolvidos. A animosidade surgida internamente e com freqüência, exposta externamente surge como parte da legitimação 


\section{DOSSIÊ OS ANOS LULA}

dos agentes junto aos profanos ${ }^{3}$ e, freqüentemente, é assumida pelos iniciados como um verdadeiro teatro. Para os profanos, a manutenção desse estranho equilíbrio é exibida como uma necessidade, que só pode ser explicada oficialmente pelo discurso da ética profissional de cada campo. As modificações no campo não podem ultrapassar determinados limites, ou os agentes não poderão manter a sua existência. Assim, mesmo que de forma inconsciente, todos os agentes trabalham para esse resultado. Desse modo, não há jogo se os participantes não concordam com os seus limites, suas regras e objetivos, o que implica que deve existir uma referência cultural comum $^{4}$ a todos, elevada à altura de outro capital, o capital cultural, para fornecer os elementos do jogo e, principalmente, legitimá-lo, tanto para os próprios agentes como para os profanos. Esse capital engendra em grande parte a cumplicidade objetiva citada pelo autor, a cuja adesão também estão expostos os agentes, sob pena de não serem aceitos entre os pares. Essa compreensão, quando inexistente, faz com que os eventuais atritos entre agentes sejam levados às últimas conseqüências, o que pode levar à áspera exclusão do menos capitalizado ou mesmo à inviabilização de carreiras ou projetos de inclusão nas hierarquias internas do campo.

A adesão a esse acordo não verbal deverá ser medida e controlada pelos agentes estabelecidos e permanecerá em nível superficial, opinativo ou doxa, como define o autor, de modo a inferir também a capacidade demonstrada pelo agente de avaliar a correlação de forças diante de si e orientar-se dentro do campo com segurança e objetividade. Ao mesmo tempo, o agente deve declarar publicamente o fato de valorizar o jogo e demonstrar possuir o domínio do capital cultural $^{5}$ necessário para ser incluído. As estratégias para a aceitação

\footnotetext{
3 Profano como estranho ao campo (qualquer campo). O campo jurídico é decalcado do campo religioso, que abriu e ocupou por séculos, no Ocidente europeu, o espaço hoje assumido pelo campo estatal. Aplicam-se por homologia, aos não iniciados, as idéias de não pertencimento à religião, ignorante do respeito devido às coisas sagradas, secular, leigo e/ou estranho ou alheio às idéias ou conhecimentos sobre assuntos determinados. (Ver Boudieu, 1997; Bourdieu, 1992).

4 No caso dos agentes do campo jurídico, trata-se do certificado de graduação universitária em Direito.

${ }^{5}$ O que é feito pela utilização do vocabulário específico do campo, no caso a linguagem jurídica.
} 
final, entretanto, incluem a apresentação de avanços sobre os limites do jogo, cujo surgimento leva ao que o autor denomina revoluções parciais, que muito mais chamam a atenção para o seu autor no sentido de sua legitimação como candidato digno do campo, do que para o conteúdo do novo produto. Por esses meios pode o novo agente demonstrar suas capacidades e merecimento, sem ameaçar o campo. O autor não credita apenas à ânsia de lucros materiais e/ou simbólicos o móvel das ações dos agentes, mas também à relação entre o habitus, ou sistema mental interno de referências de cada agente, e as condições encontradas em cada campo específico, na maior parte das vezes realizada de modo inconsciente. A relação entre o que o agente almeja objetivamente e o que almeja subjetivamente é muitas vezes bastante afastada, havendo espaço para idealismo real. Não há possibilidade de ação ou interesse externo desconectado do móvel interno de interesse, quer haja ou não consciência ou adequação mútua nessas estratégias. Sua intenção, declaradamente, é escapar às estreitas alternativas do finalismo, que aponta para uma pouco provável coerência e constância absolutas na consciência dos agentes em relação ao campo, e do mecanicismo, que aponta para a não existência dessa consciência, dependendo o agente inteiramente de influências externas.

Para a compreensão do campo jurídico, o conhecimento de seu efeito de monopólio é essencial: dele decorre a sua força; somente o campo jurídico pode dizer o direito, e por essa razão não é estranho que magistrados de diferentes correntes se unam em torno desse monopólio (ROCHA, 2002). O confronto interno entre os agentes do campo jurídico é real, e, muitas vezes, envolve altos níveis de agressividade na disputa pela imposição das interpretações da lei pelos interessados. Mas na realidade, por trás dessa animosidade existe, com grau maior ou menor de compreensão e de aceitação por parte dos envolvidos, um arranjo de sobrevivência, ou de manutenção de ambas as posições, pelo conhecimento e reconhecimento dos agentes quanto à referência cultural comum a todos, o conhecimento jurídico. Este estabelece as visões de mundo impostas pelos dominantes no grupo social, e que passam a ser naturalizadas pelo trabalho desses agentes, que desse 
modo podem fixar as fronteiras do campo, e criar a sua autonomia, baseada essencialmente na crença da neutralidade dos magistrados. A partir dessa crença básica, aliada ao monopólio do conhecimento e da interpretação das leis, a autonomia do campo jurídico se torna de tal modo forte, que pode o mesmo, para os seus integrantes, assumir o papel de todo-poderoso criador e modificador de todas as realidades, materializando desse modo a crença no Estado.

Não existe uma ponte teórica para a aplicação deste aparato conceitual ao caso brasileiro, e as dificuldades que esse fato acarreta: o que se pode distinguir numa primeira aproximação, entretanto, é o modo pelo qual se estrutura o campo jurídico, quando o autor cita a concorrência pelo monopólio de dizer o direito. Entre nós, o campo se estrutura também em torno desta concorrência, que legitima seu objeto em relação aos concorrentes, na medida em que eles se interreconhecem, estabelecendo relações de competição em torno de qual interpretação da lei será declarada válida no caso concreto, em razão do monopólio específico do campo jurídico de dizer o direito. Os agentes, nesse embate, se desgastam, entram em atrito, mas nenhum deles coloca em cheque a validade e a existência do campo, visto que da existência deste depende muitas vezes a própria existência (ou sobrevivência) do agente. Assim é que a existência do campo pressupõe oposições internas entre seus agentes, algumas bastante fortes e consagradas na visão popular, mas que do ponto de vista oficial, não apresentam nenhum suporte teórico ou mesmo fático consistente. No caso brasileiro, entretanto, as relações assim organizadas, decorrentes da lógica impessoal própria do modelo de Estado europeu, estão perpassadas por lógicas sociais imbricadas a questões pessoais dos agentes do campo, em especial à lógica da sobrevivência e da reprodução social, dinamizadas por uma lógica da reciprocidade, inerente à socialização do agente, não superada pelo habitus jurídico, adquirido muito posteriormente. No contexto do modelo de Estado europeu, a lógica do trabalho do campo jurídico se insere na lógica da conservação, e dessa forma, constitui um dos mais importantes elementos fundadores da ordem simbólica, fundadora da ordem social. 
A sistematização e a racionalização às quais estão submetidas as normas jurídicas e a hierarquia de normas utilizadas para a sua justificativa reforça o efeito dessa lógica, ao fazer considerar-se universal o ponto de vista dos agentes dominantes. Por esse efeito, é possível uniformizar as práticas, marcando o tecido social com características interessadas tornadas universais.

O discurso do campo jurídico, ou do Direito, representa, em grande parte, a opção de seus agentes por uma visão de mundo, a dos grupos sociais dominantes, a qual passa a se inscrever e a ser absorvida nas lógicas sociais, de tal sorte que não mais é questionada, tornandose natural. As leis, mesmo que inicialmente sofram resistência, com o tempo acabam por serem reconhecidas como úteis, e assim, passam a fazer parte do patrimônio cultural da coletividade. As leis são inicialmente apresentadas pelos agentes do campo político, mas só se efetivam na realidade como instituições jurídicas, a partir do que passam a ser exigidas como tal por seus destinatários (os profanos), que as assumem como referência natural. Em grandes sociedades diferenciadas, esse mecanismo de universalização, a cargo do Direito, é um dos meios mais poderosos pelos quais a dominação simbólica é levada a efeito, criando na realidade a imposição legítima da ordem social. Surge o efeito de normalização, que fornece autoridade social que permite aos seus detentores obter a plena eficácia prática da coerção jurídica. Desse modo a regularidade, ou aquilo que se faz regularmente, é transformado em regra (aquilo que se faz de regra). Em conseqüência, as instituições naturais ao grupo são transformadas em instituições jurídicas, naturalizadas. O jurista, nessa mecânica, fica submisso ao corpo das leis elaboradas para justificar a dominação estabelecida, e a necessidade de sua atuação. Surge daí uma concorrência entre os agentes do campo jurídico que, sob a aparência de antagonismo, na verdade trocam vantagens entre si. O corpo da lei é, desse ponto de vista, uma espécie de reservatório central de autoridade, que garante a força dos atos jurídicos singulares. É desse modo que se compreende que os juristas se inclinem comumente ao ceticismo, e os magistrados, em especial, justifiquem-se como 
intérpretes oficiais, apoiados apenas na lei, como se fosse possível a neutralidade. Entretanto, para aplicar a lei o juiz precisa criar, ainda que pouco, mas procura sempre dissimular esse ato sob um discurso técnico neutro, pois segundo a crença desses agentes, a lógica prevalecente deve pertencer ao Estado, já que somente a autoridade abstrata deste, ao final, não será contestada.

Os magistrados detêm, inclusive legalmente, a posição de supremacia no campo jurídico, e tal fato determina a existência de uma espécie de sub-campo judicial, cujos contornos em relação ao campo jurídico, entretanto, são imprecisos, devido à necessidade incontornável de todos os agentes de compartilhar crenças (ou dogmas) comuns, entre os quais, em especial, a da existência possível de um lugar de neutralidade (o Judiciário) na ação do Estado. Os juristas, ainda que extraoficialmente declarem o contrário, se dispõem a declarar oficialmente a crença na neutralidade ou no jargão jurídico, imparcialidade do magistrado. Mesmo vista com ceticismo, a crença na neutralidade é difundida externamente aos profanos, pois é fundamental para a manutenção do campo. Se os profanos fossem levados a descrer na imparcialidade dos julgamentos, a própria existência do campo estaria comprometida, e com ela as vantagens econômicas e simbólicas decorrentes, para seus integrantes. Por essa razão, os magistrados detêm um lugar de primazia no campo, e essa definição da neutralidade é deixada para a doxa, já que sua exploração epistemológica se revela inútil e perigosa, pois se tal fosse realizado, somente se poderia inutilizá-la como pressuposto fundamental de legitimação para todos os atos dos agentes de Estado, a começar pelos agentes do campo jurídico.

Inversamente ao que ocorre no campo jurídico, que vive e se mantém em torno de uma noção de relativa autonomia quanto aos demais campos, decorrente de métodos internos de recrutamento e seleção de magistrados, advogados, procuradores, etc., o campo político depende diretamente da legitimação externa: ao final de mandatos limitados no tempo, os parlamentares deverão, obrigatoriamente, submeter-se novamente ao processo eleitoral, para tentar continuar inseridos no campo. A constante preocupação dos agentes com a sua 
legitimação para obter a recondução à posição no campo, por reeleição introduz a lógica eleitoral, o elemento mais importante para a orientação de suas ações. Nesse sentido é de se observar que o Judiciário pode, em contrário, ignorar oficialmente as pressões da mídia em torno de uma imagem de seus integrantes em relação à opinião pública, pois a nomeação ou consagração de seus integrantes, e sua manutenção ou eventual exclusão é inteiramente referida a parâmetros internos do campo jurídico; para os juízes não há legitimação externa por via eleitoral. Desde a seleção, passando pelas promoções (e os critérios de antiguidade e merecimento), a ocupação de cargos estratégicos da hierarquia interna (Presidência, Corregedoria, etc.) e promoção externa (porta-voz, etc.) até o modo como se dá a aposentadoria, tudo é controlado pelas instâncias superiores do próprio Judiciário. O recurso a meios externos de consagração, como a mídia, que podem beneficiar alguns agentes do campo jurídico, como advogados, por exemplo, resulta em efeito inverso no interior do campo jurídico quantos aos agentes do Judiciário, pois permite ao agente escapar, ainda que temporariamente, ao rígido controle interno, desautorizando a hierarquização e pois arriscando sua estabilidade: esse comportamento mais cedo ou mais tarde levará o agente a expor-se a sanções internas, produzindo efeitos negativos em sua carreira. Tal, porém, não ocorre no campo político, onde a seleção do agente já se dá por meio externo ao campo, o processo eleitoral. Pouco espaço existe para as manipulações eleitorais, como a transferência de votos de um candidato a outro, pois não há como garanti-la, embora no caso brasileiro essa regra tenha sido muitas vezes burlada. A relação com os eleitores não pode ser levada oficialmente para o campo, pois a sua existência como campo também depende da exclusão dos representados. Os agentes que integram o campo político se encontram, desse modo, em posição mais delicada em relação aos destinatários de seus serviços do que os agentes do Judiciário. E ao contrário da crença externa corrente, o seu acesso e a obtenção de efeitos oferecem dificuldades muito maiores do que as próprias ao campo jurídico. Por exemplo, não há como o campo político agir em determinado sentido, sem que as demandas que são 


\section{DOSSIÊ OS ANOS LULA}

encaminhadas até seus agentes sejam preliminarmente transpostas para seus códigos internos de referência, não determinados necessariamente por lei, mas, antes de tudo, por uma agenda ideológica, decorrente da proposição, características e estratégias próprias de cada partido.

\section{A indicação como problema}

Iniciamos com a referência constitucional: os artigos 88, inciso XIV, e 101, parágrafo único, da Constituição Federal Brasileira de 1988 (BRASIL, 2010), instituem a nomeação dos juízes do Supremo Tribunal Federal, que após aprovação pelo Senado federal, assumem a vaga em aberto, com o título de Ministro do Supremo Tribunal Federal, que não se confunde com o título de Ministro relativo aos atores nomeados para as pastas ministeriais do Executivo Federal. Observe-se que o mecanismo jurídico citado, introduz um elemento suposto, uma maior possibilidade de persistência das ideologias adotadas pelo Presidente da República que fez a indicação, embora não exista obrigatoriedade legal de manter-se o nomeado fiel à sua origem (MARANHÃO, 2003), como adiante será visto. É preciso destacar, entretanto, que esse mecanismo de indicação é hoje bastante criticado (OLIVEIRA, 2008), por sua carcaterística de mera formalidade quanto ao papel do Senado Federal, justamente pela percepção de que o mesmo comprometeria a neutralidade, ou imparcialidade judicial $^{6}$, característica que legitima externamente a ação de todos os agentes do Judiciário, e que, desse modo, seria prejudicada por um mecanismo de politização ou partidarização, de seus membros (MACHADO, 2007).

São muito recentes, entre nós, as abordagens que procuram relacionar as ações do Supremo Tribunal Fedeal com a dinâmica da política que desenvolve fora de seus limites. Embora seja um órgão

\footnotetext{
6 O termo imparcialidade (neutralidade) no jargão dos juristas, designa uma crença partilhada pelos integrantes do campo social jurídico, a qual legitima a força do Direito junto aos grupos sociais. Embora seja parte da illusio que sustenta a visão interna do campo, o termo é também utilizado na legitimação externa do grupo, para sustentar a afirmativa de que as decisões judiciais seriam, necessariamente, fruto de raciocínios lógicos, neutros, resultando portanto, em sentenças sempre justas (BOURDIEU, 1989).
} 
previsto democraticamente, representando direta ou indiretamente a sociedade, e detendo poder de veto, (TAYLOR, 2007) o Judiciário, de um modo geral, ainda é visto como um ente estatal com ação isolada, e referido a um algo (o conjunto de leis em vigor, ou ordenamento jurídico) que deveria ser neutro, ou que mantivesse o comportamento de seus integrantes razoavelmente sob controle, dentro de uma determinada previsibilidade. Essa previsibilidade, portanto, poderia ser de algum modo conduzida, ou manobrada externamente, por aquele que detém legalmente, o poder de indicar aqueles que ocuparão as vagas de Ministro do Supremo Tribunal Federal, o titular do Poder Executivo nacional, o Presidente da República.

Deve ser destacado o estudo levado a cabo por Claudia Türner e Mariana Mota Prado (2009), no qual as autoras procuram elucidar o processo pelo qual o ocupante da vaga de Presidente utiliza, estrategicamente, essa prerrogativa, para manter sua influência nas decisões de políticas públicas no país. Segundo as mesmas, seriam duas essas estratégias: primeiro, maximizar o número de pessoas nomeadas para cargos com estabilidade ou com mandatos fixos; e segundo, prolongar ao máximo a permanência de seus nomeados nos respectivos cargos. Segundo essa perspectiva, se constatado, o sucesso do eventual Presidente nessas ações, deixaria claro que não existiria o tradicional papel judicial de contestação da pressão das maiorias parlamentares, e ainda mais, a suposta neutralidade técnica na interpretação constitucional, pelos seus integrantes, não passaria de simples fachada legitimatória para manobras políticass externa ao Supremo. Essa última, entretanto, é uma interpretação simplista, normalmente feita por aqueles que querem estender ao Judiciário a mesma lógica de comportamento dos demais Poderes.

Evidentemente, as características da ação desse poder deve ser levada em conta ao interpretar as interações da ação do Supremo com os demais atores políticos, mas daí a imaginar que seus integrantes apresentarão um comportamento semelhante ao de parlamentares comprometidos com suas bancadas e bases de apoio eleitoral, vai uma longa distância. Muitos aspectos dessa dinâmica ainda devem ser 
elucidados para o caso brasileiro. Seria necessário estudar, em especial, a influência do corpo técnico de assessores dos Ministros, sejam esses concursados ou indicados por cargos em comissão, influência essa muito maior do que podem supor aqueles que não pensam nos efeitos das ações daqueles que, efetivamente, dão conta dos milhares de processos judiciais distribuídos, anualmente, a cada Ministro.

Desse modo, a indicação dos Ministros do STF resulta de um complexo jogo de interações entre as estratégias dos diversos grupos de atores políticos interessados, o que torna difícil crer que, em algum momento, pudesse prevalecer apenas a vontade pessoal do ocupante do Executivo federal. Concordamos com a perspectiva de Ribeiro e Arguelhes (2009), segundo a qual é preciso levar em consideração, no mínimo, duas classes de fatores, que denominam internos e externos ao Supremo Tribunal Federal, sendo que esses últimos podem, em muitos momentos, determinar o afastamento dos Ministros nomeados das posições ou alinhamentos que, eventualmente, tenham decidido sua indicação. Esses fatores de influência decorrem, em grande parte, do que denominamos Presidencialismo de Coalizão, pelo qual muitos interesses e pressões devem ser pesados antes de ser adotada uma decisão final, dado que não exclui as decisões políticas afetas aos Ministros do Supremo. Ao mesmo tempo, é preciso destacar que essa dinâmica, evidentemente, diminui, em muito, a expectativa que o Presidente possa ter, quanto à eventual manutenção do alinhamento dos Ministros que tenha nomeado.

\section{Os usos políticos das indicações}

Preliminarmente, relatamos que o Presidente Luiz Inácio Lula da Silva indicou, até o momento, oito Ministros para o Supremo Tribunal Federal. Pela ordem, são eles: Antonio Cezar Peluso, Carlos Alberto Ayres de Freitas Britto, Joaquim Benedito Barbosa Nunes, Eros Roberto Grau, Enrique Ricardo Lewandowski, Cármen Lúcia Antunes Rocha, Carlos Alberto Menezes Direito e José Antonio Dias Toffoli. Tendo um deles falecido (Carlos Alberto Direito), e outro se aposentado (Eros Roberto Grau), atualmente (outubro/2010) estão em exercício sete 
deles, dentre o total de onze Ministros do Supremo Tribunal Federal. A vaga deixada em aberto pela aposentadoria do Ministro Eros Roberto Grau continua sem ser preenchida, tudo indicando que à próxima Presidente se reservará a indicação, como provável parte de uma estratégia de legitimação política da mesma, evitando-Ihe a resistência oposta à primeira indicação feita por Lula. O Ministro Antonio Cezar Peluso foi primeiro Ministro a ser indicado pelo Presidente Lula, após forte resistência, interna e externamente ao STF. Por essa razão, cremos, deu-se a a escolha de seu perfil; o agente é magistrado de carreira; e sua escolha pode estar também relacionada às fortes críticas relacionadas a um suposto desprestígio da Magistratura nacional pelo governo de Fernando Henrique Cardoso, e a uma politização do STF, como indicavam as origens legislativas de alguns Ministros, hoje aposentados, e indicados por outros Presidentes, especialmente Antônio Carlos Jobim, indicado pelo então Presidente Fernando Henrique Cardoso. A indicação de Carlos Alberto Ayres de Freitas Britto, advogado, parece contemplar uma busca de equilíbrio para com a Magistratura, e ao mesmo tempo, prestigiar a OAB (Ordem dos Advogados do Brasil), por apoio político, como ator social integrante da chamada sociedade civil. Já a indicação de Joaquim Benedito Barbosa Nunes, por Lula, sendo o agente afrodescendente, soou como o rompimento de um tabu social, como representou a nomeação da Ministra Ellen Gracie Northfleet, primeira mulher a ocupar uma vaga de Ministro do STF, por Fernando Henrique Cardoso. Entretanto, segundo dados fornecidos pelo próprio STF, ele seria o terceiro negro a ser indicado para o cargo. De origem social humilde, oriundo do Ministério Público Federal, com uma sólida carreira no serviço público e um currículo digno de um intelectual de alto nível, sua indicação reforçou simbolicamente o objetivo da administração Lula, de divulgar a valorização de pessoas competentes, originadas de grupos sociais comumente marginalizados, como o próprio Presidente Lula. O nome de Eros Roberto Grau, também advogado, mas muito mais destacado como jurista e professor da USP (Universidade do Estado de São Paulo), veio atender à pressão dos grupos universitários, por uma indicação que 
prestigiasse o meio acadêmico. Embora o seu nome tenha sido criticado em razão de sua anterior militância política, e por publicações, não de natureza técnica, mas literária laudatória, algo controversa, tal não afetou a decisão presidencial, que sinalizou desse modo sua flexibilidade quanto ao perfil e ao passado de seus indicados. O nome de Enrique Ricardo Lewandowski, originalmente advogado, por sua indicação, volta a prestigiar a Magistratura, uma vez que esse Ministro apresenta, em seu currículo, longos anos de dedicação ao Judiciário do Estado de São Paulo, embora não tenha o mesmo ingressado por aprovação em concurso público, mas por indicação a uma das vagas destinadas à $\mathrm{OAB} / \mathrm{SP}$, no chamado Quinto Constitucional. Desse modo, sua indicação pode indicar um esforço no sentido de ganhar as simpatias, tanto da magistratura, como da $O A B$ nacionais. A indicação de Cármen Lúcia Antunes Rocha, anteriormente Procuradora Geral do Estado de Minas Gerais, e professora da PUC-MG, segunda mulher nomeada como Ministrado do STF, indica a busca de neutralizar preventivamente a crítica potencial de uma suposta resistência do Governo Lula quanto a mulheres. Ao mesmo tempo, prestigia o público eleitor feminino e católico do Estado de Minas Gerais, abrindo caminho para a candidata de Lula à Presidência da República. O nome de Carlos Alberto Direito, advogado, como indicado de Lula ao STF, reforça a busca de apoio pelo Governo Lula junto à $O A B$ nacional. Esse Ministro, entretanto, faleceu dois anos após, em 2009, ensejando assim a indicação de Carlos Alberto Toffoli, também advogado, mas oriundo dos quadros internos do Partido dos Trabalhadores, o qual sofreu resistência interna e externa, por sua pouca idade e produção intelectual, para os padrões do STF, além de parecer indicar uma certa ideologização dos critérios de indicação. Observe-se que, imediatamente após sua posse, com grande pompa, numa cerimônia para cerca de mil convidados, ocorreu a denúncia de que a festa teria sido financiada com dinheiro público, pela Caixa Econômica Federal; o que o mesmo respondeu alegando desconhecer a origem do financiamento da cerimônia. Em termos de análise, no que se refere aos cálculos políticos e motivações que conduziram às indicações dos agentes mencionados acima, é preciso destacar dois níveis de 
objetivos políticos, ligados às justificativas para as indicações presidenciais: com Ribeiro e Arguelhes (2009), destacamos os fins externos e os fins internos à dinâmica de ação do Supremo Tribunal Federal. Esses autores destacam que, externamente, a nomeação de cada Ministro pode estar ligada a eventuais barganhas por apoio político a iniciativas presidenciais. Esse tipo de barganha é pontual e eventual, dado que a indicação de uma determinada pessoa pode ou não representar, no momento da abertura da vaga, a possibilidade de uma negociação relevante para o Executivo nacional. O uso da indicação como moeda de troca para apoio político é, na verdade, pouco eficiente, especialmente por não depender mais a manutenção do Ministro no cargo, após a nomeação, do Presidente da República. Além do mais, é preciso destacar a forte vinculação do trabalho jurídico dos Ministros à orientação do texto constitucional, à tradição do pensamento jurídico (expresso na jurisprudência, os textos das decisões reiteradas dos julgados, adotadas pelos Tribunais com força de lei), à influência da formação, conhecimentos, pesquisas e trabalhos de seus assessores e, ainda, à dinâmica de decisões colegiadas, isto é, finalizadas por votação entre os Ministros. Ao mesmo tempo, as indicações de Ministros podem obedecer, pura e simplesmente, a uma lógica de promoção ou difusão de uma determinada imagem, pelo Presidente, ao atender a demandas por representação de grupos tão grandes e difusos, como negros e mulheres. Externamente, embora não tenha o Supremo Tribunal Federal uma função de representação política do grupo social, é de extremo relevo, para o Presidente, difundir uma imagem de preocupação social, pela ação de, aparentemente, interferir na composição interna do órgão máximo do Judiciário nacional, um órgão de Estado tradicionalmente egresso das elites nacionais, e, portanto, submisso à conservação dos interesses objetivos desses grupos. É pouco provável, entretanto, que dessas ações do Presidente Lula, ou de qualquer outro ocupante do Executivo nacional, resulte algum lucro político significativo, dado que, em termos nacionais, o Judiciário não integra o imaginário social brasileiro como parte do Estado, e ainda menos a hierarquia superior interna desse Poder (ROCHA, 2002). 
Internamente, a expectativa sobre o resultado da indicação do Presidente deveria recair sobre o conteúdo, ou definição dos votos dos Ministros, em cada ação ou processo judicial, visto individualmente. Em teoria, do ponto de vista jurídico, a produção do voto deveria brotar da consciência do agente, orientada de modo neutro, pelos princípios constitucionais, para uma solução justa. objetivamente, entretanto, a subjetividade contida nesse processo é dificilmente previsível. Embora objeto de muitos estudos, há muito tempo, (VIANNA, BURGOS e SALLES, 2007) esse processo só é razoavelmente avaliado por seus resultados, que podem ser registrados e estudados estatisticamente. Entretanto, essas análises não permitem prever o comportamento futuro dos Ministros, quanto a seus votos (MARANHÃO, 2003). Ainda segundo Ribeiro e Arguelhes (2009), esses atores pesarão os efeitos de suas decisões sobre os demais Poderes e interessados, o que é necessariamente feito, em decorrência da característica colegiada (coletiva) das decisões do STF. Pode-se pensar, especulativamente, na expressão da tendência do voto, pela orientação pessoal de cada Ministro, mas não garantir o resultado, o qual, se estiver alinhado com o interesse do Presidente que veio a indicar determinado Ministro (a), não parece haver mais do que simples coincidência. É preciso, portanto, levar em consideração todas as motivações que orientam as decisões de cada Ministro. Nas justificativas de cada voto, dentro dos processos levados ao STF, devem transparecer as tendências, mas também o efeito de eventuais pressões políticas e/ou argumentativas, dentro da lógica do debate processual jurídico, que podem, evidentemente, ser utilizadas como apoio para quaisquer orientações de sentido do voto, embora o tom da linguagem jurídica, por sua natureza, procure mascarar as influências pessoais internas e/ou externas sofridas por cada um desses atores, as quais determinam, necessariamente, o resultado do julgamento individual, que definirá o voto.

\section{Conclusões}

Finalizando, podemos observar que a confrontação dessas lógicas interna e externa, pode ser produtivamente desenvolvida pela teoria dos 
campos sociais, referida inicialmente, e pela qual, o dado mais relevante nesse tipo de estudo é o modo como se dá a produção de estratégias de ação e dos discursos, para consumo interno e externo, na manutenção da legitimidade do Supremo, e da sua posição de força no embate dos interesses submetidos à apreciação dos Ministros. Esse problema se agrava, devido à constatação da impossibilidade da manutenção do tradicional discurso de alienação da lei em relação à política, uma dinâmica aparentemente paradoxal, uma vez que, ao mesmo tempo em que conduz ao desenvolvimento político das relações entre os Poderes de Estado, enfraquece a legitimidade da recente crença no Judiciário como bastião de lutas individuais e coletivas, contra os interesses imediatos dos atores que, eventual e temporariamente, assumem esses Poderes. Essa dinâmica, por si só, justifica toda uma linha de pesquisas que, lentamente, vem crescendo nas Ciências Sociais brasileiras.

Não se poderá afirmar, portanto, sobre o governo Lula, que tenha tido sucesso em haver, supostamente, transformado, muito menos ideologicamente, o perfil do Supremo Tribunal Federal, apesar do alto número de nomeações cometidas a esse Presidente, dadas as razões antes elencadas, assim como não se pode afirmar o mesmo dos governos anteriores, mesmo os do período autoritário militar. A autonomia de que dispõe cada Ministro, depois de tomar posse, além do seu forte vínculo com a manutenção da ordem jurídica constitucional, (vínculo representado, objetivamente, no trabalho técnico de seus assessores) dados que legitimam sua posição de poder, impedem que se aceite a simplória expectativa de alinhamento, comprometimento ou controle desse $\mathrm{s}$ agentes pelo Presidente que o nomeou, o mesmo ocorrendo em relação a eventuais grupos de interesse/apoio que tenham influenciado em sua nomeação. Esse mecanismo faz sentido em relação à percepção de que existiria no Brasil, historicamente, uma pouco estudada (e algo inusitada) tradição de acatamento e submissão às decisões do Judiciário, quando sustentadas pelo Supremo Tribunal Federal, por parte dos demais Poderes do Estado brasileiro, o que se reproduziria nos demais órgãos da Administração direta e indireta, assim como nos Tribunais das demais Unidades da Federação. Embora 
essa observação ainda seja especulativa, e dependa de pesquisas que a corroborem, é notório que a manutenção da ordem jurídica brasileira, em especial no que concerne às questões de direito privado (por exemplo, propriedade, heranças, pensões, etc.) representa alguns dos mais caros interesses de diversos segmentos sociais brasileiros, cujos representantes junto ao Estado, conscientemente ou não, colaboram para a legitimação e manutenção da força do Supremo Tribunal Federal entre nós, independemente do caráter dos governos, ou Presidentes da República que, eventualmente, indiquem seus integrantes.

Álvaro Filipe Oxley da Rocha é Doutor em Direito do Estado (UFPR), Mestre em Ciência Política (UFRGS), Professor Titular do PPGCCrim da PUC-RS.

E-mail: alvaro.rocha@pucrs.br

\section{Referências:}

ALMEIDA, Frederico Normanha Ribeiro de. A advocacia e o acesso a justiça no estado de São Paulo (1980-2005). 2005. 133 f. Dissertação (Mestrado em Ciência Política) - Departamento de Ciência Política, Universidade de São Paulo, [2005]. Disponível em: <http://www.teses.usp.br/teses/disponiveis/8/8131/tde-26062007155516/publico/TESE_FREDERICO_NORMANHA_RIBEIRO_ALMEIDA.pdf >. Acesso em: 10 nov. 2010.

BONELLI, Maria da Gloria. Ideologias do profissionalismo em disputa na magistratura paulista. Sociologias, Porto Alegre, n. 13, p. 110-135, jan.jun. 2005.

BOURDIEU, Pierre. O Poder Simbólico. Lisboa: DIFEL, 1989.

Gênese e estrutura do campo religioso. In: . $A$

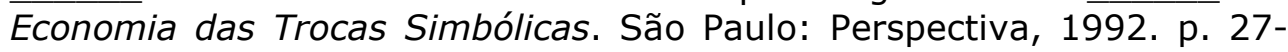
78.

. Sobre a Televisão. Rio de Janeiro: Jorge Zahar Ed., 1997.

BRASIL. Constituição Federal de 1988. Disponível em: <http://www.planalto.gov.br/ccivil_03/Constituicao/>. Acesso em: 10 nov. 2010. 
COMMAILLE, Jacques. L'esprit sociologique des lois: essai de sociologie politique du droit. Paris: Presses Universitaires de France, 1994.

DEZALAY, Yves; GARTH, Bryant. Law, Lawyers and Social Capital: Rule of Law Versus Relational Capitalism. Social Legal Studies, London, v. 6, n. 1, p. 109-141, mar. 1997.

ENGELMANN, Fabiano. Capital Internacional e hierarquização do campo jurídico no Brasil. Disponível em: <http://crbc.ehess.fr/docannexe.php?id=434>. Acesso em: 10 nov. 2010.

KOERNER, Andrei. Judiciário e Cidadania na Constituição da República Brasileira. São Paulo: HUCITEC, 1998.

MACHADO, Diana Soares. A politização do STF diante do mecanismo de escolha de seus Ministros. Brasília: O Autor, 2007.

MARANHÃO, Tatiana P. A. Quando o Supremo Tribunal Federal discorda do Presidente da República. 2003. 174 f. Dissertação (Mestrado em Ciência Política) - Programa de Pós-graduação em Ciência Política, Universidade de Brasília, [2003].

OLIVEIRA, Fabiana Luci. Justice, Professionalism, and Politics in the Exercise of Judicial Review by Brazil's Supreme Court. Brazilian Political Science Review, Rio de Janeiro, v. 2, n. 2, p. 128-202, jul.-dez. 2008.

PINTO, Louis. Pierre Bourdieu e a teoria do mundo social. Rio de Janeiro: FGV, 2000.

RIBEIRO, Leandro Molhano; ARGUELHES, Diego Werneck. Processo Decisório, Judiciário e Políticas Públicas: levando a decisão judicial a sério. In: ENCONTRRO ANUAL DA ANPOCS, 33. 2009, Caxambu. Disponível em: < http://www.anpocs.org.br/portal/component/option,com_docman/task,c at_view/gid,84/Itemid,85/>. Acesso em: 10 nov. 2010.

ROCHA, Alvaro Filipe Oxley da. Sociologia do Direito: a magistratura no Espelho. São Leopoldo: Editora da UNISINOS, 2002.

SADEK, Maria Tereza (Org.). Magistrados: uma imagem em movimento. Rio de Janeiro: Editora FGV, 2006.

SANTOS, André Marenco dos; DA ROS, Luciano. Caminhos que levam à Corte: carreiras e padrões de recrutamento dos ministros dos órgãos de cúpula do Poder Judiciário brasileiro (1829-2006). Revista de Sociologia e Política, Curitiba, v. 16, n. 30, p. 131-149, jun. 2008.

TAYLOR, Matthew. O Judiciário e as Políticas Públicas no Brasil. Dados, Rio de Janeiro, v. 50, n. 2, p. 229-257, 2007. 
TRUBEK, David et. al. Global Restructuring and the Law: studies of the Internationalization of Legal Fields and the Creation of Transnational Arenas. Case Western Reserve Law Review, Cleveland, v. 44, n. 2, p. 407-498, 1994.

TURNER, Cláudia; PRADO, Mariana. A Democracia e seu Impacto nas Nomeações dos Diretores das Agências Reguladoras e Ministros do STF. Revista de Direito Administrativo, São Paulo, v. 250, n. 115, p. 27-74, jan. 2009.

VAUCHEZ, Antoine; WILLEMEZ, Laurent. La justice face ses formateurs (1980-2006). Entreprises de modernization et logiques de résistances. Paris: PUF, 2007. (Coll. Droit et justice).

VIANNA, Luiz Werneck; BURGOS, Marcelo Baumann; SALLES, Paula Martins. Dezessete anos de judicialização política. Tempo Social Revista de Sociologia da USP, São Paulo, v. 19, n. 2, p. 39-85, nov. 2007.

Texto recebido em 26/09/2010.

Aprovado em 02/12/2010. 